Lasser Nd : YAG điều trị đục bao sau thứ phát sau phấu thuât đăt thể thủy tinh nhân tao hâuu phòng tại cộng đồng, Luận án tiến sĩ y học, Trường Đại học Y Hà Nội.

2. Vasavada A.R., Raj S.M., Shah G.D.,Nanavaty M.A. (2013), Posterior capsule opacification after lens implantation: incidence, risk factors and management, Expert Review of Ophthalmology, 8(2), 141- 149.

3. Prajna N. V ., Ellwein L. B., Selveraj S. Manjula K.,Kupfer C. (2000), The Madurai Intraocular Lens Study IV: Posterior Capsule Opacification, American Journal of Ophthalmology, 130(3), $304-309$.

4. Bhargava R., Kumar P., Phogat H.,Chaudhary K. P. (2015), Neodymium - Yttrium Aluminium
Garnet Laser Capsulotomy Energy Levels for Posterior Capsule Opacification, Journal of Ophthalmic and Vision Research, 10 (1), 37-42.

5. Phạm Thị Kim Thanh (2004). Nghiên cứu đục bao sau thể thủy tinh thứ phát sau phấu thuât đắt thể thủy tinh nhân tạo và biện pháp xử lý, Luận án tiến sĩ y hoc, Trường Đai hoc Y Hà Nôi.

6. Nguyển Mạnh Hải (2019), Đánh giá kết quả mở bao sau thế thủy tinh bằng laser Nd-YAG trên mắt mổ phaco có đăt kính nôi nhãn, Luận văn chuyên khoa II, Trường Đại học Y̛ Hà Nội.

7. Vyas V. J., Ahir L. D.,Ratna B. (2016), To Study the Visual Outcome After Nd:-YAG laser Posterior Capsulotomy, International Journal of Science and Research, 5(10), 55 - 57.

\title{
ĐĂC ĐIỂM CHİ SỐ TIM CỔ CHÂN Ở BÊNH NHÂN ĐÁI THÁO ĐƯỜNG TYP 2 LOÉT BÀN CHÂN TẠI BỆNH VIỆN NộI TIẾT TRUNG ƯƠNG
}

\section{TÓM TẮT}

Mục tiêu: Mô tả đặc điểm chỉ số mạch cổ chân (CAVI)ở bênh nhân đái tháo đường typ 2 loét bàn chân tại Bệnh viện Nội tiết Trung ương. Đối tượng và phương pháp nghiên cứu: Nghiên cứu mố tả cắt ngang 176 bệnh nhân đái tháo đường typ 2có loét bàn chân đáp ứng tiêu chuẩn lựa chọn vào nghiên cứu. Kết quả: Tuổi trung bình nhóm nghiên cứu là $61,99 \pm 11,11$. Nam nhiều hơn nữ (59,7\% và 40,3\%). Thời gian mắc bệnh trên 10 năm là $58,5 \%$. Trung bình CAVI bên phải là $9,41 \pm 2,72$; CAVI bên trái là $9,27 \pm 2,23$ và CAVI trung bình là $9,34 \pm 2,29$. Trung bình CAVI không liên quan đến giới tính $(p>0,05)$. Trung bình CAVI nhóm ĐTÐ có THA cao hơn nhóm ĐTÐ không THA $(9,85 \pm 2,15$ so với $8,37 \pm 2,25$, $\mathrm{p}<0,05)$. Kết luận: Trung bình CAVI ở bệnh nhân ĐTÐ có LBC tăng cao hơn bình thường. THA làm ảnh hưởng đến trung bình chỉ số CAVI.

Tư khóa: mạch cổ chân CAVI, đái tháo đường typ 2, loét bàn chân

SUMMARY

CHARACTERISTICS OF CARDIO-ANKLE VASCULAR INDEX IN PATIENTS WITH DIABETES MELLITUS TYPE 2 WITH FOOT ULCERS AT THE NATIONAL HOSPITAL OF ENDOCRINOLOGY

Objective: To characterize the Cardio-ankle

\footnotetext{
${ }^{1}$ Bênh viên Nôi tiết trung ương

${ }^{2}$ Học viện Quân Y

${ }^{3}$ Dai hoc Y Hà Nôi

Chịu trách nhiệm chính: Bùi Thế Long

Email: bslong80@gmail.com

Ngày nhận bài: 9.4.2021

Ngày phản biện khoa học: 25.5.2021

Ngày duyệt bài: 9.6.2021
}

\section{Bùi Thế Long1, Đoàn Văn Đệㄹㄹ Bùi Mỹ Hạnh ${ }^{3}$}

vascular index (CAVI) in patients with type 2 diabetes with foot ulcers at Hospital of Endocrinology. Study object and method: A cross-sectional descriptive study of 176 patients with diabetes mellitus type 2 with foot ulcers who met the inclusion criteria for the study. Results: The mean age of the study group was $61.99 \pm 11.11$. More men than women $(59.7 \%$ and $40.3 \%)$. The disease duration over 10 years is $58.5 \%$. The mean CAVI on the right is $9.41 \pm 2.72$; The left CAVI was $9.27 \pm 2.23$ and the mean CAVI was $9.34 \pm 2.29$. Mean CAVI was not related to sex $(p>0.05)$. The mean CAVI in the diabetic group with hypertension was higher than that in the nonhypertensive group $(9.85 \pm 2.15$ compared with 8.37 \pm 2.25 , $p<0.05)$. Conclusion: Average CAVI in patients with type 2 diabetes with foot ulcers increased higher than normal. Hypertension affects the mean CAVI.

Key words: Cardio-ankle vascular index, type 2 diabetes, foot ulcers

\section{I. ĐĂT VẤN ĐỀ}

Đái tháo đường (ĐTĐ) týp 2 là môt bênh nôi tiết - chuyển hóa thường gặp, tỷ lệ mắc đái tháo đường ngày càng gia tăng. Một trong các biến chứng có thể gây tàn phế cho người bệnh là biến chứng bàn chân đái tháo đường. Chỉ số tim - cổ chân (Cardio-Ankle Vascular Index - CAVI) là một chỉ số đánh giá độ cứng của mạch máu dựa trên nguyên lý của vận tốc lan truyền sóng mạch (PWV). Nhiều tác giả trên thế giới khuyến cáo sử dụng CAVI trên lâm sàng để khảo sát, sàng lọc và theo dõi xơ vữa động mạch đặc biệt ở những bệnh nhân nguy cơ cao như Đái tháo đường typ 2[1]. Ở Việt Nam những năm gần đây đã có một số nghiên cứu về chỉ số CAVI trên những nhóm bệnh nhân có bệnh lý tim mạch 
như tăng huyết áp, bệnh động mạch vành hay suy thận [2] Tuy nhiên chưa có công trình nghiên cứu nào đánh giá chỉ số CAVI, homocystein và đo độ dầy lớp nội trung mạc động mạch chi dưới ở người bệnh đái tháo đường, đặc biệt ở nhóm đái tháo đường có loét bàn chân. Chính vì vậy, chúng tôi tiến hành nghiên cứu này với mục tiêu mô tả đăc điểm chỉ số mạch cổ chân ở bệnh nhân đái tháo đường typ 2 loét bàn chân điều trị tại Bệnh viện Nội tiết Trung Ương.

\section{II. ĐỐI TƯỢNG VÀ PHƯƠNG PHÁP NGHIÊN CỨU}

2.1. Đối tượng nghiên cứu: 176 bệnh nhân được chẩn đoán đái tháo đường typ 2 có loét bàn chân đang điều trị nội trú tại bệnh viện nội tiết Trung ươngđồng ý tham gia nghiên cứu, không mắc bệnh cấp tính (shock, đột quy, NMCT...) và bệnh lý mãn tính khác.

\subsection{Phương pháp nghiên cứu}

\subsubsection{Nghiên cứu mô tả cắt ngang}

2.2.2. Phương pháp phân tích số liệu: Số liệu sau khi thu thập sẽ được làm sạch, nhập liệu bằng phần mềm Epidata 3.1 và phân tích bằng phần mềm SPSS 16.0. Thống kê bao gồm tần số và tỷ lệ được tính toán cho các biến số và chỉ số quan tầm.

\subsubsection{Các bước tiến hành nghiên cứu:}

* Khám lâm sàng, làm bệnh án nghiên cứu, đăng ký các triệu chứng lâm sàng có trên bệnh nhân.

* Bênh nhân được làm các xét nghiệm: công thức máu, sinh hóa máu, đo chỉ số Tim - bàn chân, Siêu âm mạch chi dưới, Định lượng nồng độ Homocystein huyết thanh.

* Lựa chọn bệnh nhân nghiên cứu theo tiêu chuẩn nghiên cứu. Bệnh nhân đủ tiêu chuẩn được lấy máu, tách huyết tương và bảo quản mẫu ở âm $70^{\circ} \mathrm{C}$ cho đến khi xét nghiệm Homocyctein.

* Các thông tin, dữ liệu bệnh án của mỗi bệnh nhân được ghi chép vào bệnh án nghiên cứu

* Lập bảng tổng hợp số liệu, xử lý phân tích số liêu.

* Đánh giá kết quả và viết báo cáo

III. KẾT QUẢ VÀ BÀN LUÂ̂N

Bảng 1. Thông tin chung của đối tượng nghiên cứu ( $n=176)$

\begin{tabular}{|c|c|c|c|}
\hline \multirow{2}{*}{ Đặc điểm chung } & \multicolumn{2}{c|}{ ĐTÐ có LBC } \\
\cline { 2 - 4 } & $\mathbf{n}$ & $\mathbf{\%}$ \\
\hline \multirow{2}{|c|}{ Tuổi (TB \pm SD) } & $61,99 \pm 11,11$ \\
\hline \multirow{2}{*}{ Giới tính } & Nam & 105 & 59,7 \\
\cline { 2 - 4 } & Nữ & 71 & 40,3 \\
\hline \multirow{2}{*}{$\begin{array}{l}\text { Thời gian } \\
\text { mắc ĐTĐ }\end{array}$} & Phát hiện lần đầu & 7 & 4 \\
\cline { 2 - 4 } & Dưới 5 năm & 36 & 20,5 \\
\hline
\end{tabular}

\begin{tabular}{|c|c|c|c|}
\hline & $5-$ dưới 10 năm & 30 & 17 \\
\cline { 2 - 4 } & $10-$ dưới 15 năm & 46 & 26,1 \\
\cline { 2 - 4 } & Trên 15 năm & 57 & 32,4 \\
\hline
\end{tabular}

Trong báo cáo này, tuổi trung bình đối với nhóm ĐTÐ có loét bàn chân là $61,9 \pm 11,1$ tuổi. Kết quả tương tự nghiên cứu hầu hết các tác giả trong và ngoài nước đã phản ánh một thực tế bênh nhân ĐTÐ bị LBC có tuổi đời khá cao. Tuổi đời bệnh nhân bị LBC khá cao là do đa số bệnh nhân trong các nghiên cứu đều là bệnh nhân ĐTĐ týp 2. Không những vậy, tổn thương $L B C$ đã được chứng minh là một trong những biến chứng muộn của bệnh ĐTĐ๋ nên thường gặp ở những bệnh nhân có thời gian phát hiện bệnh ĐTĐ lâu năm, mắc nhiều biến chứng và khổng kiểm soát tốt glucose máu.

Tỷ lệ nam cao hơn nữ: có $59,7 \%$ là nam và $40,3 \%$ là nữ. Tuy có khác biệt về tỷ lệ giới tính nhưng sự khác biệt này không có ý nghĩa thống kê. Hiện nay, đa số các kết quả nghiên cứu (KQNC) đều cho thấy tổn thương LBC do ĐTĐ gặp nhiều ở nam giới hơn so với nữ giới. Nguyên nhân của sự khác nhau này có thể do các thống kê về tỷ lệ mắc các biến chứng có nguy cơ gây ra LBC như BCTKNV và bệnh ĐMNV gặp ở nam giới nhiều hơn. Theo nghiên cứu của Dinh $T$ và cộng sự, nam giới có tổn thương thần kinh ngoại vi nặng hơn và có sự gia tăng áp lực bàn chân cao hớn so với nữ [3].

Thời gian mắc bệnh ĐTÐ chủ yếu là trên 10 năm $(58,5 \%)$. Thời gian phát hiện bệnh ĐTĐ cũng được coi là yếu tố có giá trị tiên lượng khả năng hình thành LBC. Nguy cơ xuất hiện LBC tăng cao theo thời gian mắc bệnh ĐTĐ là do người mắc bênh ĐTĐ càng lâu sẽ̃ có nhiều biến chứng dẫn tới $\mathrm{LBC}$ như BCTKNV, bệnh ĐMNV, tai biến mạch máu não, biến chứng mắt, khả năng kiểm soát glucose máu kém...

Bảng 2. Trung bình chỉ số CAVI, bề dày nội mạc chi dưới, nồng độ Homocystien của 2 nhóm ĐTÐ loét chân và không loét chân ( $n=176)$

\begin{tabular}{|c|c|}
\hline Chỉ số & ĐTÐ có LBC (TB \pm SD) \\
\hline CAVI bên phải & $9,41 \pm 2,72$ \\
\hline CAVI bên trái & $9,27 \pm 2,23$ \\
\hline CAVI trung bình & $9,34 \pm 2,29$ \\
\hline
\end{tabular}

Trong nghiên cứu của chúng tôi, trung bình CAVI nhóm nghiên cứu tương đồng nhau giữa bên phải, bên trái và CAVI trung bình (lần lượt là $9,41 \pm 2,72 ; 9,27 \pm 2,23 ; 9,34 \pm 2,29)$. Kết quả này cao hơn nghiên cứu của Mehmet và cộng sự [4] $8,22 \pm 0,18 \mathrm{~m} / \mathrm{s}$ ở bệnh nhân ĐTÐ và và nhóm chứng 7,59 $\pm 0,17 \mathrm{~m} / \mathrm{s}$ ); Park So Young và cộng sự tiến hành một nghiên cứu hồi cứu 
trên 219 bệnh nhân mắc ĐTĐ typ 2 thu được kết quả CAVI trung bình là $8,2 \pm 1,4$, trong đó, đa số bệnh nhân có CAVI <8 (47,0\%); 28,3\% bệnh nhân có CAVI từ 8 đến dưới 9 và $24,7 \%$ bệnh nhân có CAVI từ 9 trở lên [1]. Tương tự nghiên cứu của Teonchit Nuamchit và cộng sự cho kết quả CAVI trung bình là $8,99 \pm 1,23$ [5].

Bảng 3. So sánh mức độ CAVI giữa các nhóm nghiên cứu

\begin{tabular}{|c|c|}
\hline Giá trị CAVI & $\begin{array}{c}\text { ĐTÐ có LBC } \\
(\mathbf{n = 1 7 6 )} \mathbf{\%}\end{array}$ \\
\hline Chỉ số CAVI bên phải & \\
\hline$<8$ & 18,9 \\
\hline $8<9$ & 16,6 \\
\hline$\geq 9$ & 64,6 \\
\hline Chi số CAVI bên trái & \\
\hline$<8$ & 18,9 \\
\hline $8<9$ & 17,7 \\
\hline$\geq 9$ & 63,4 \\
\hline Chỉ số CAVI trung bình \\
\hline$<8$ & 19,0 \\
\hline $8<9$ & 17,8 \\
\hline$\geq 9$ & 63,2 \\
\hline
\end{tabular}

Trong nghiên cứu này, đa số bệnh nhân có chỉ số CAVI từ 9 trở lên. Tỷ lệ đối tượng có CAVI $\geq 9$ của nhóm ĐTĐ có LBC $(63,2 \%)$ cao hơn nhóm ĐTÐ không LBC $(46,4 \%)$ ( $p<0,001)$. Kết quả của chúng tôi cao hơn so với kết quả của tác giả Kim Kwang Joon nghiên cứu trên 320 bệnh nhân ĐTĐ typ 2 có $20 \%$ bệnh nhân tăng CAVI ( $\geq 9)$ [6]

Bảng 4. Trung binh chỉ số CAVI theo giới tính và tăng huyết áp của các đôî tượng nghiên cứlu ( $n=176)$

\begin{tabular}{|c|c|}
\hline \multirow{2}{*}{ Chỉ số CAVI } & ĐTÐ có LBC (n=176) \\
\cline { 2 - 2 } & TB \pm SD \\
\hline \multicolumn{2}{|c|}{ Giới tính } \\
\hline Nam & $9,41 \pm 2,24$ \\
\hline Nữ & $9,24 \pm 2,37$ \\
\hline p & $>0,05$ \\
\hline \multicolumn{2}{|c|}{ Tăng huyết áp (THA) } \\
\hline THA & $9,85 \pm 2,15$ \\
\hline Không THA & $8,37 \pm 2,25$ \\
\hline p & $<0,05$ \\
\hline
\end{tabular}

Trong nghiên cứu của chúng tôi, trung bình CAVI ở nam giới không chênh lệch nhiều so với nữ giới. Kết quả tương tự được tác giả Yusuke Mineoka và cộng sự báo cáo vào năm 2012 trên 371 bệnh nhân ĐTĐ typ 2 có nghi ngờ lâm sàng về bệnh mạch vành cho thấy trung bình CAVI ở nam là $8.9 \pm 1.7$ và nữ là $8.7 \pm 1.5$, sự khác biệt chưa có ý nghĩa thống kê [7].

Trong nghiên cứu này, trung bình CAVI ở nhóm có THA cao hơn nhóm không THA $(p<0,05)$. Kết quả này tương tư nghiên cứu của Yusuke Mineoka và cộng sự với trung bình CAVI ở nhóm THA và không THA lần lượt là $9.3 \pm 1.6$ và $8.3 \pm 1.5(p<0,0001)$. Hơn nữa, phân tích mối tương quan chứng minh rằng tuổi, huyết áp tâm thu và đường huyết lúc đói là những biến số độc lập liên quan đến CAVI (tuổi: $r=0,509$, $p<0,001$; huyết áp tâm thu: $r=0,392, p<0,001$; đường huyết lúc đói: $r=0,319, p=0,001$ ). Namekata và cộng sự báo cáo rằng huyết áp tâm thu và huyết áp tâm trương và CAVI trung bình của $B N$ ĐTÐ và tiền ĐTÐ cao hơn đáng kể so với những người không bị ĐTĐ [8].

\section{KẾT LUẬN}

$\checkmark$ Trung bình CAVI ở bệnh nhân ĐTÐ có LBC tăng cao hơn bình thường.

$\checkmark$ Trung bình chỉ số CAVI nhóm ĐTÐ THA cao hơn nhóm ĐTÐ không THA.

\section{TÀI LIỆ THAM KHẢO}

1. Park So Young, Chin Sang Ook, Rhee Sang Youl et al (2018), "Cardio-ankle vascular index as a surrogate marker of early atherosclerotic cardiovascular disease in Koreans with type 2 diabetes mellitus", Diabetes \& metabolism journal. 42(4), 285-295.

2. Bùi Mỹ Hanh (2017), "Một số yếu tố liên quan đến độ xơ cứng mach máu ở bệnh nhân suy thận man chay thân nhẩn tao chu lỳ sử dung phương pháp đo chỉ số tim - mắt cá chân (CAV̀I)", Tạp chî Nghiên cứu y học, 46-52.

3. Dinh Thanh, Veves Aristidis (2008), "The influence of gender as a risk factor in diabetic foot ulceration", Wounds: a compendium of clinical research and practice. 20(5), 127-131.

4. Mert M., Dursun B., Yağcı A. B. et al (2020), "Cardio-ankle vascular index is linked to deranged metabolic status, especially high $\mathrm{HbA1c}$ and monocytechemoattractant-1 protein, in predialysis chronic kidney disease", Int Urol Nephrol. 52(1), 137-145.

5. Nuamchit T., Siriwittayawan D., Thitiwuthikiat P. (2020), "The Relationship Between Glycemic Control and Concomitant Hypertension on Arterial Stiffness in Type II Diabetes". 16, 343-352.

6. Kim Kwang Joon, Lee Byung-Wan, Kim Hyun-min et al (2011), "Associations Between Cardio-Ankle Vascular Index and Microvascular Complications in Type 2 Diabetes Mellitus Patients", Journal of Atherosclerosis and Thrombosis. 18(4), 328-336.

7. Mineoka, Y.; Fukui, M.; Tanaka, M. et al (2012), "Relationship between cardio-ankle vascular index (CAVI) and coronary artery calcification (CAC) in patients with type 2 diabetes mellitus", Heart Vessels. 27(2), 160-5.

8. Namekata T., Shirai K., Tanabe, N. et al (2016), "Estimating the extent of subclinical arteriosclerosis of persons with prediabetes and diabetes mellitus among Japanese urban workers and their families: a cross-sectional study", BMC Cardiovasc Disord. 16, 52. 